\title{
Mutual regulation of the Hippo/Wnt/LPA/TGF- $\beta$ signaling pathways and their roles in glaucoma (Review)
}

\author{
XIN WANG $^{1}$, GUOLI HUAI ${ }^{1}$, HAILIAN WANG $^{2}$, YUANDE LIU $^{3}$, PING $^{4}{ }^{4}$, WEI SHI $^{4}$,

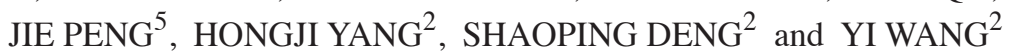

\begin{abstract}
${ }^{1}$ Department of Biomedical Engineering, Medical School of University of Electronic Science and Technology of China, Chengdu, Sichuan 610054; ${ }^{2}$ Personalized Drug Therapy Laboratory of Sichuan Province, Department of Pharmacy, Sichuan Academy of Medical Science and Sichuan Provincial People's Hospital, Chengdu, Sichuan 610072; ${ }^{3} 91388$ Military Hospital, Zhanjiang, Guangdong 524022; Departments of ${ }^{4}$ Pediatrics and ${ }^{5}$ Ophthalmology, Sichuan Academy of Medical Science and Sichuan Provincial People's Hospital, Chengdu, Sichuan 610072, P.R. China
\end{abstract}

Received October 18, 2016; Accepted December 15, 2017

DOI: $10.3892 / \mathrm{ijmm} .2017 .3352$

\begin{abstract}
Glaucoma is the leading cause of irreversible blindness worldwide and there is no effective treatment thus far. The trabecular meshwork has been identified as the major pathological area involved. Certain signaling pathways in the trabecular meshwork, including the Wnt, lysophosphatidic acid and transforming growth factor $\beta$ p pathways, have been identified as novel therapeutic targets in glaucoma treatment. Meanwhile, it has been reported that key proteins in these pathways, particularly the primary transcription regulator Yes-associated protein (YAP) and transcriptional co-activator with PDZ-binding motif (TAZ), exhibit interactions with the Hippo pathway. The Hippo pathway, which was first identified in Drosophila, has drawn great focus with regard to various aspects of studies in recent years. One role of the Hippo pathway in the regulation of organ size was indicated by more recent evidence. Defining the relevant physiological function of the Hippo pathway has proven to be extremely complicated. Studies have ascribed a role for the Hippo pathway in an overwhelming number of processes, including cell proliferation, cell death and cell differentiation. Therefore, the present review aimed to unravel the roles of YAP and TAZ in the Hippo pathway and the pathogenesis of glaucoma. Furthermore, a new and creative study for the treatment of glaucoma is provided.
\end{abstract}

Correspondence to: Dr Yi Wang, Personalized Drug Therapy Laboratory of Sichuan Province, Department of Pharmacy, Sichuan Academy of Medical Science and Sichuan Provincial People's Hospital, Chengdu, Sichuan 610072, P.R. China

E-mail:w_yi@yahoo.com

Dr Jie Peng, Department of Ophthalmology, Sichuan Academy of Medical Science and Sichuan Provincial People's Hospital, Chengdu, Sichuan 610072, P.R. China

E-mail: 1483905150@qq.com

Key words: glaucoma, Hippo, Yes-associated protein, transcriptional co-activator with PDZ-binding motif, Wnt, lysophosphatidic acid, transforming growth factor- $\beta$

\section{Contents}

1. Introduction

2. Regulation of the Hippo pathway

3. Regulation of the Wnt/ $\beta$-catenin signaling pathway in glaucoma and the interaction with YAP/TAZ

4. Regulation of LPA in glaucoma and the mutual regulation with YAP/TAZ

5. Regulation of the TGF- $\beta /$ Smad signaling pathway in glaucoma and the interaction with YAP/TAZ

6. Role of the YAP/TAZ gene in the development of glaucoma

7. Conclusions

\section{Introduction}

Primary open-angle glaucoma (POAG) is a major type of glaucoma (1). High intraocular pressure (IOP), optic nerve damage and visual field defects are the main pathological features of POAG, with high IOP being the most common. Although the clinical features of glaucoma are well described, the pathological mechanisms that cause these features are likely to be diverse and require further elucidation. The main pathological region of POAG has been located at the trabecular meshwork (2), which is responsible for the regulation of the aqueous humor outflow. In addition, a balance between the production and outflow of the aqueous humor can control IOP. The trabecular meshwork is composed of layers of trabecular beams, and is surrounded by elastic fibers, fibronectin (FN) and laminin (LM). The outermost layer is formed of trabecular cells, which can secrete extracellular matrix (ECM) components and transduce ECM signals $(2,3)$. Additionally, the structural abnormalities of the ECM, as well as the dysfunction of the trabecular meshwork and Schlemm's canal (SC), are involved in high IOP (4). In recent years, signaling pathways, including the Wnt, lysophosphatidic acid (LPA) and transforming growth factor- $\beta$ (TGF- $\beta$ ) pathways, have been found to be associated with the development of glaucoma in the trabecular meshwork. In the study of the pathogenesis of glaucoma, the Wnt pathway has been considered as a novel interventional path for the treatment of glaucoma via 
regulation of the IOP (5). Simultaneously, the LPA pathway was also indicated as a novel target to reduce IOP. In glaucoma, LPA is upregulated and its inhibitors can reduce IOP (6). Furthermore, the concentration of TGF- $\beta$ in the aqueous humor of POAG patients is markedly high. TGF- $\beta$ enhances aqueous outflow resistance through promoting the synthesis of the ECM (7). Notably, in the process of understanding the Wnt, LPA and TGF- $\beta$ pathways, it was found that they are all closely linked to Yes-associated protein (YAP) and transcriptional co-activator with PDZ-binding motif (TAZ), which are the radical transcription regulators of the Hippo pathway $(6,8,9)$. As a tumor suppressor pathway, the Hippo pathway serves important roles in diverse biological processes, including cell death, differentiation and proliferation (10). However, study of the Hippo pathway in ophthalmology remains relatively rare. Therefore, the present review will focus on recent advances in our understanding of the molecular components of these major signaling branches and the various levels of regulation of signaling in glaucoma.

\section{Regulation of the Hippo pathway}

The Hippo pathway, which was first discovered in Drosophila, is a novel signaling pathway. Considered as a tumor suppressor pathway, it plays a fundamental role in the determination of cell death, cell differentiation $(10,11)$ and cell proliferation $(12-15)$ during organ size development. The Hippo pathway in Drosophila includes Warts (Wts) (16), Salvador (Sav) (17), Hippo (Hpo) (18), Mob-as-tumor-suppressor (Mats) (19) and Yorkie (Yki) (12). Hpo phosphorylates Wts through its interaction with Sav, then phospho-Wts phosphorylates Yki, which is the main downstream effect factor of the Hippo pathway (20). Subsequently, Yki binds with the transcription factor Scalloped (Sd) (21). Sd interacts with its downstream regulatory protein Mat (22), and this results in the inactivation of Yki (21). The inactivated Yki increases its nuclear distribution, enhances the protein stability and inhibits the expression of the downstream genes $(12,13)$ to inhibit cell proliferation and induce apoptosis. The Hippo pathway has also been identified in mammals, and the corresponding homologous proteins are Lats1/2 (Wts), Sav1 (Sav), Mst1/2 (Hpo), Mob1 (Mats) and YAP/TAZ (YAP and TAZ are each homologous proteins of Yki) (20). Transcriptional enhancer factor TEF-1 (TEAD) is the ortholog of Sd and the major DNA-binding domain of YAP (23) (Fig. 1). The revolution of the Hippo pathway is highly conserved in mammals (24), and it exhibits similar signaling to that found in Drosophila (23). The present review will mainly focus on the regulation of the Hippo pathway in mammals.

Fat is a kind of protein encoded by the fat gene. Pez is an evolutionarily conserved FERM domain protein containing a protein tyrosine phosphatase (PTP) domain. Fat (25,26), Pez (27) and junction-related proteins, including Expanded (Ex) (28), Merlin (Mer) (28,29), Kibra (30), neurofibromin 2 (NF2) $(28,31)$ and Crumbs (Crb) (32), have been identified as upstream regulators of the Hippo pathway. Although the regulatory mechanism of the Hippo pathway remains unclear, an increasing number of studies have provided evidence that the Hippo pathway is tightly correlated with the external environment and regulated by the extracellular factors $(15,33,34)$. The Fat complex that is composed of Ex, Mer and Kibra can activate the Hippo pathway through phosphorylating Hpo and increase the stability of Ex protein $(35,36)$. Ex and Mer, membrane-associated proteins, contain the four-point-one, ezrin, radixin, moesin (FERM) domain and can interact with a variety of cell scaffold proteins and transmembrane proteins through the N-terminal region of Ex and the C-terminal domain of Mer, which is characteristic of the protein 4.1 family. It has been reported that their interactions are involved in regulating cell apoptosis, cell proliferation and the cell cycle (37). Kibra protein, which contains WW and C2 domains, activates Wts via interaction with Ex and Mer (38). In addition, NF2, as a homologous protein of Mer and a tumor suppressor gene, is a negative regulator of cell growth. The mutation of NF2 causes central nervous system tumors, such as neurofibromatosis (39). With conditional knockout of the NF2 gene in the mouse liver, the risk of cancer is increased greatly (40). Additionally, Crb, a transmembrane protein, can also regulate the Hippo pathway (41). Crb has a large extracellular domain and a short intracellular domain. For the $\mathrm{Crb}$ cytoplasmic tail, it has two recognized motifs. One links to the spectra and actin cytoskeleton (PDZ-binding motif) and the other is the juxtamembrane FERM-domain binding motif (JM), which interacts with polarity regulatory factors, including Stardust (Sdt), PALS1-associated tight junction protein (Patj) and partitioning defective 6 (Par6). By interacting with the JM of $\mathrm{Crb}$, Ex expression is inhibited, which ultimately results in an increase in Yki activity and increased organ growth $(32,41)$. Pez, a newly found binding partner of Kibra $(27,38)$, is a type of FERM domain protein containing the protein tyrosine phosphatase domain. Pez, as a component of upstream Hippo signaling, serves an important role in cell metabolism, proliferation and differentiation, particularly with regard to restricting the activity of Yki in the adult midgut epithelium (27). Meanwhile, transcriptional levels of the target gene of Yki have been elevated in Pez mutant guts (42).

The core transduction pathway of Hippo is a kinase cascade. As a tumor suppressor, Mst1/2 was the first factor to be identified (43). Mst1/2, a member of the nuclear Dbf2-related protein family, encodes kinase and can phosphorylate Sav1, Lats1/2 and Mob (44,45). Stimulus signals of the Hippo pathway activate Mst1/2, then Mst1/2 phosphorylates Lats1/2 through its interaction with Sav1, which increases the activity of Mst1/2 (45). Sav1 serves a pivotal role in connecting Msts1/2 to Lats1/2 (17), and it can increase or decrease the activity of Lats1/2 after being phosphorylated by Mst1/2 (46). Lats1/2 can negatively regulate the cell cycle, the ectopic expression of Lats 2 can inhibit the transformation from the cellular G1 period to the S period (47), and the overexpression of Lats1/2 will lead to the stagnation of the cellular G2/M period and apoptosis $(48,49)$. Subsequent to being phosphorylated by Mst1/2, Mob1 combines with Lats1/2, which leads to the activation of Lats1/2 (45). Afterward, Lats1/2 phosphorylates YAP/TAZ (20) (Fig. 1). An increasing number of studies have illustrated that the highly conservative peculiarity of Hippo pathway is involved in the growth of tissues and organs, and tumorigenesis $(10,13,16,28,31,50,51)$. Deficiency of Mst1/2 will lead to the enlargement of the liver in mice, finally inducing a tumor (52). However, when upstream kinase is not activated, YAP/TAZ translocates into the nucleus to serve a role in gene expression (Fig. 1).

Found in 1994, YAP binds to the SH3 region of the Yes protein in the Src protein kinase family through the sequence 'PVKQPPPLAP' and is a protein with a molecular weight of 


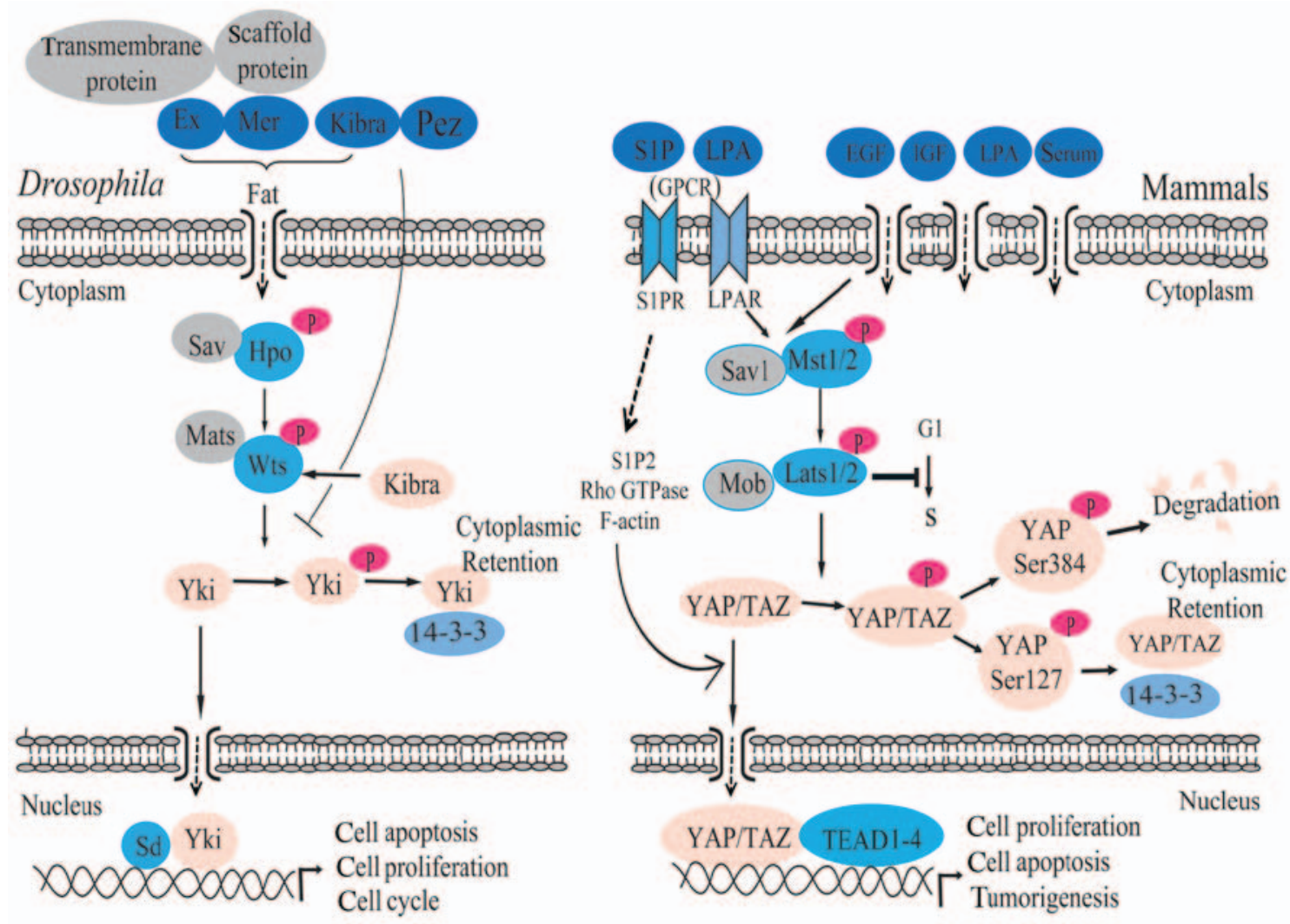

Figure 1. Core components of the Hippo pathway. Willin is the upstream signaling molecule. Mst1/2, Lats $1 / 2$, Sav1 and Mob are the core components of the Hippo pathway. Willin stimulates Mst 1/2, then Mst 1/2 phosphorylates Lats1/2 via interaction with Sav1. Lats1/2 phosphorylates YAP/TAZ via interaction with Mob, leading to cytoplasmic retention and degradation of YAP/TAZ through phosphorylation of YAP Ser384 and binding of YAP Ser127 to 14-3-3 protein. When the kinase cascade is inactivated, phosphorylated YAP/TAZ translocate into the nucleus and generate gene expression via interaction with TEAD. YAP, Yes-associated protein; TAZ, transcriptional co-activator with PDZ-binding motif; Ex, expanded; Mer, Merlin; Sav, Salvador; Hpo, Hippo; Wts, Warts; Yki, Yorkie; Sd, scalloped; S1P, sphingosine-1-phosphate; LPA, lysophosphatidic acid; GPCR, G-protein-coupled receptor; EGF, epidermal growth factor; IGF, insulin-like growth factor; S1PR, sphingosine-1-phosphate receptor; LPAR, Lysophosphatidic acid receptor; Mst1/2, Hpo orthologs; Lats1/2, Wts orthologs; Sav1, Sav orthologs; Mob, Mats orthologs; G1, the gap before DNA replication; S, DNA synthetic phase; TEAD, transcriptional enhancer activator domain.

about $65 \mathrm{kDa}(53,54)$. YAP is located on chromosome $11 \mathrm{q} 22$ in humans $(55,56)$. The YAP protein contains one or two WW structure domains, a 14-3-3 protein binding site, a SH3 binding motif, a PDZ binding motif of the C-terminal, an insertion in the N-terminal TEAD-binding region, a proline-rich domain of the amino-terminal and a coiled-coil structure domain of the transcriptional regulation structure (57). YAP can interact with a variety of proteins, includimg angiomotin family proteins, TEADs and $\mathrm{Sd}$, and it can participate in multiple signaling transduction pathways in cells through the structure domains and amino acid sequences (57). YAP is a type of multifunctional cell connection protein and transcription activating factor, with a variety of structural domains and specific sequences that determine the diversity of its role. The transcriptional activity of YAP depends on its intracellular localization (24). When YAP is located in the nucleus, it can activate gene transcription through interaction with transcription activation factors, and then the phosphorylated YAP transposes into the cytoplasm and accumulates there (58). The cytoplasmic localization of phosphorylated YAP can prevent or terminate its activation activity in the nucleus $(51,59)$. Due to the interaction with phosphorylated Ser127 and 14-3-3 proteins, accumulating YAP cannot transpose into the nucleus, causing YAP to lose its role as a transcription activation factor $(58,60)$.
First identified in 2000, TAZ can also combine with 14-3-3 proteins and is a type of protein composed of 400 amino acids containing a WW domain and a PDZ domain (61). Through sequence comparison, it has been revealed that TAZ is the homologous protein of YAP, as well as exhibiting the function of transcriptional activation (20). The coding gene of TAZ is located on chromosome $3 \mathrm{q} 24$, and its molecular weight is $45 \mathrm{kDa}(61)$. The combination of 14-3-3 proteins and TAZ requires phosphorylation of the 89th TAZ serine, as the TAZ Ser89 area is one of the best combination sequences of 14-3-3 proteins and is known as RSXpSXP. The other is RXY/FXpSXP, and both can be recognized by the varyiong types of 14-3-3 proteins (62). YAP possesses the same feature of the combination sequences $(61,62)$. TAZ has the same transcriptional activation function as YAP. YAP, TAZ and Yorkie all lack DNA binding domains. Therefore, they can only regulate transcription via activation (little inhibition) of the activity of transcription factors. The upstream regulatory mechanisms produce the 14-3-3 protein binding sites via phosphorylation of TAZ Ser89 with a kinase, and then control TAZ cytoplasmic retention. Thus, the transcriptional regulation of TAZ is inhibited $(61,63)$.

YAP/TAZ are the major downstream effectors of the Hippo pathway. Due to the lack of DNA-binding domains, YAP/TAZ act by connecting with other transcription factors, including 
TEAD/TEF family transcription factors (50). When YAP Ser127 is phosphorylated by Lats $1 / 2$, it generates a 14-3-3 protein binding site $(58,63)$. Lats2 promotes the cytoplasmic accumulation of YAP by promoting YAP Ser127 phosphorylation and the combination of YAP and 14-3-3 proteins $(60,64)$. YAP Ser384, which is phosphorylated by Lats1/2, promotes casein kinase 1 (CK1) to phosphorylate YAP Ser384, and leads to the degradation of YAP $(65,66)$ (Fig. 1). Furthermore, the activity of YAP/TAZ can be regulated by serum-derived sphingosine-1-phosphate (S1P), LPA, GPCR signaling and the actin-myosin cytoskeleton (6). S1P and LPA can induce YAP dephosphorylation, nuclear localization, activation through the $\mathrm{S}_{2} \mathrm{P}_{2}$ receptor, Rho GTPase activation and F-actin polymerization (6).

The Hippo pathway serves a crucial role in regulating organ size, cell proliferation and apoptosis, and it can maintain a stable internal environment. The inactivation of Mst1/2, Sav1, Lats1/2 and Mob1, and the overexpression of YAP/TAZ can cause an increase in the organ size, cell proliferation (14) and even tumorigenesis, including liver cancer (67), gastric cancer (68), breast cancer (69), high-grade dysplasia and adenocarcinoma of the esophagus, gastric adenocarcinoma and metastatic gastric disease (70). Furthermore, the Hippo pathway regulates the inhibition of cell contact (71). Studies have shown that normal cells, which highly express YAP, grow continuously due to mutual contact; hyperexpression of YAP can decrease contact inhibition and promote cell proliferation $(14,60,67)$. Cell contact inhibits cell growth, which is a physiological characteristic of cells. Previous studies have found that soluble growth factors, including epidermal growth factor (EGF), insulin-like growth factor, serum and LPA, can inhibit YAP/TAZ and reduce the effect of cell contact on the majority of occasions (72-74). Two newly identified downstream factors, phosphoinositide 3-kinase (PI3K) and phosphoinositide-dependent protein kinase 1, for the Hippo pathway were found to inhibit the pathway and induce YAP nuclear retention via interaction with soluble growth factors, and finally, by activating growth genes (72) (Fig. 1). Cell contact is correlated with cell density. Cell density can control the localization and phosphorylation of YAP (60). YAP locates in the nucleus at low cell density in NIH-3T3 cells and the human breast epithelial MCF10A cell line. The decrease in cell density will increase the cell area. While at high cell densities, YAP locates in the cytoplasm and exhibits slower electrophoretic migration. The electrophoretic migration is density-dependent due to the phosphorylation. Phosphorylated YAP migrates faster $(60,71)$.

\section{Regulation of the Wnt/ $\beta$-catenin signaling pathway in glaucoma and the interaction with YAP/TAZ}

The Wnt/ $\beta$-catenin signaling pathway is an extremely conservative pathway in biological evolution $(75,76)$. Wnt can secrete glycoprotein through binding with receptors on the cell membranes (77) and can activate intracellular signaling pathways, which regulate the expression of target genes. Thus, cell proliferation, differentiation and apoptosis can be regulated, and various diseases will be caused, even tumorigenesis $(75,78,79)$. Wnt pathways contain the canonical (Wnt/ $\beta$-catenin), non-canonical (Wnt/JNK pathway) and $\mathrm{Ca}^{2+}$ pathways $(80,81)$. At present, the mechanism of the canonical pathway is the most exhaustively researched. It has been found that $\beta$-catenin is the principal regulation point of the canonical Wnt pathway, and it is also the major component of cell adhesion (75). Interaction between $\beta$-catenin and E-cadherin can connect the intracytoplasmic cadherins to the actin cytoskeleton, thus allowing cell contact, adhesion and motility (75).

The Wnt/ $\beta$-catenin pathway has two states, on and off (75). Wnt is inactive in the off-state, and adenomatous polyposis coli (APC) (80), glycogen synthase kinase 3 (GSK3) (82), Axin (83) and CK1 form the $\beta$-catenin protein destruction complex. The complex mediates the phosphorylation of $\beta$-catenin, resulting in the transcription of the Wnt/ $\beta$-catenin target gene inhibited in the cytoplasm (84). In the on-state, Wnt binds with Fzd receptors on the cell surface, and they then bind with low-density lipoprotein receptor-related protein 5 or 6 (LRP5/6) to form the Wnt/Fzd/LRP5/6 complex, which phosphorylates and activates Dishevelled (Dvl) protein $(85,86)$. Subsequently, Dvl inhibits the activity of $\beta$-catenin protein destruction complex, leading to the cytoplasmic retention of $\beta$-catenin. Later, $\beta$-catenin translocates into the nucleus to form a complex with the T-cell factor family (TCF/LEF). The $\beta$-catenin/TCF/LEF complex activates the transcription of downstream target genes, including c-Myc, c-Jun and cylin D1 (87) (Fig. 2). According to studies by Gan et al (88) and Itoh et al (89), Dvl is a core component of the $\beta$-catenin/TCF/LEF complex.

The Wnt/ $\beta$-catenin and Hippo pathways regulate the expression of genes, cell proliferation, cell differentiation and cell apoptosis, so they interact mutually to a certain extent. On one hand, studies have reported that phosphorylated $\beta$-catenin can promote YAP/TAZ degradation by serving as the presenting factor $(90,91)$. On the other hand, through controlling $\beta$-catenin stability, Wnt mediates YAP/TAZ stabilization and promotes YAP/TAZ to translocate into the nucleus in a manner independent of the Hippo pathway (90) (Fig. 2). Furthermore, Axin is not only associated with the $\beta$-catenin protein destruction complex, but is also strongly associated with endogenous YAP/TAZ $(92,93)$. When Axin1/2 or APC is knocked out, YAP/TAZ will accumulate in the nucleus, which indicates that Wnt regulates YAP/TAZ through promoting their nuclear accumulation $(80,83)$.

YAP is the target gene of Wnt/ $/$-catenin. TEAD binds with the domain of phosphorylated YAP, and then directly connects to the $\mathrm{N}$-terminal of $\beta$-catenin and promotes $\beta$-catenin nuclear translocation. It has been demonstrated that the Hippo pathway antagonizes signal transduction of the Wnt pathway (94). Meanwhile, TAZ is a downstream regulator of Wnt signaling (90). Based on the study by Varelas et al (8), TAZ can combine with Dvl protein and prevent the phosphorylation of Dvl by Wnt, resulting in the inhibition of the Wnt pathway (Fig. 2). The Hippo pathway may inhibit the expression of the target Wnt gene through altering the activity of $\beta$-catenin. Studies have revealed that TAZ degradation requires $\beta$-catenin phosphorylation, and the combination of phosphorylated YAP/TAZ and $\beta$-catenin, which will cause the accumulation of $\beta$-catenin in the cytoplasm; thus, the activity of $\beta$-catenin transcription is inhibited $(90,95)$. The localization of $\beta$-catenin is enhanced in the cytoplasm and nucleus in TAZ mutant kidneys in mice (8). Together, these results suggest that the Hippo pathway can negatively regulate the activity of $\beta$-catenin transcription.

Studies have indicated that the $\mathrm{Wnt} / \beta$-catenin pathway is the chief Wnt pathway in human trabecular meshwork (HTM) cells and that it serves a role in regulating IOP (5). Secreted frizzled-related protein 1 (sFRP1), the Wnt pathway inhibitor, 


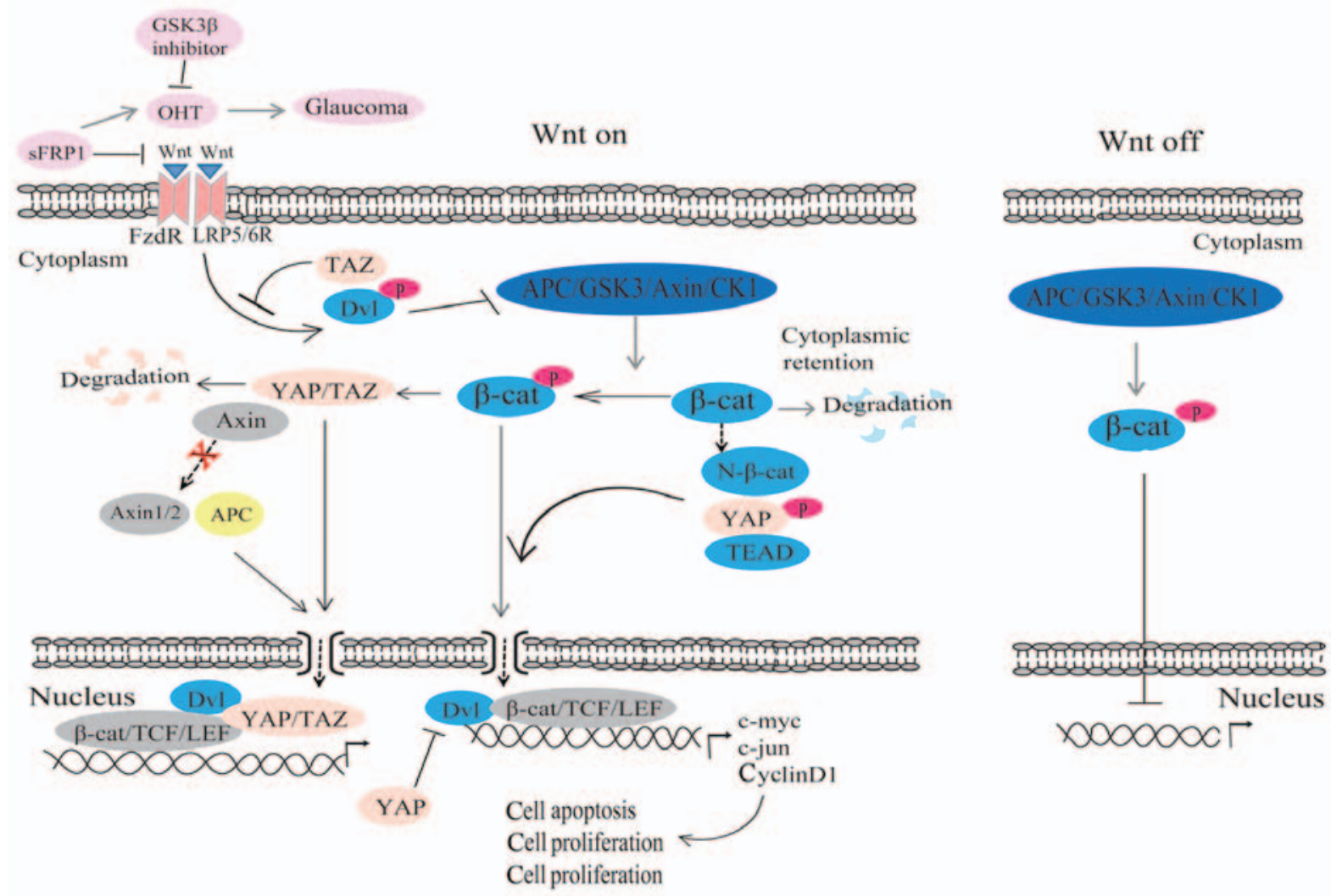

Figure 2. Regulation of the Wnt/\$-catenin signaling pathway. In the off-state, APC, GSK3, Axin and CK1 form into the APC/GSK3/Axin/CK1 complex, which mediates the phosphorylation of $\beta$-catenin, repressing Wnt/ $\beta$-catenin target gene transcription in the cytoplasm. In the on-state, Wnt binds with receptor Fzd and LRP5/6, forming into the Wnt/Fzd/LRP5/6 complex, and then phosphorylates and activates Dvl. Next, Dvl inhibits the activity of the APC/GSK3/Axin/CK1 complex, causing $\beta$-catenin to accumulate in the cytoplasm and then translocate into the nucleus to form a complex with the TCF/LEF family and induce gene expression. Phosphorylated $\beta$-catenin promotes degradation of TAZ via interaction with YAP/TAZ. sFRP1 inhibits $\beta$-catenin, which is inhibited by GSK3 $\beta$ and induces OHT, resulting in primary open-angle glaucoma. TEAD, transcriptional enhancer factor TEF-1; APC, adenomatous polyposis coli; GSK3, glycogen synthase kinase 3; CK1, casein kinase 1; LRP5/6, low-density lipoprotein receptor-related protein 5 or 6; Dvl, Dishevelled; TAZ, transcriptional co-activator with PDZ-binding motif; YAP, Yes-associated protein; sFRP1, secreted frizzled-related protein 1; OHT, ocular hypertension; sFRP1, secreted frizzled-related protein 1; OHT, ocular hypertensive; FzdR, frizzled receptors; LRP5/6R, low-density lipoprotein receptor-related protein 5 or 6; TAZ, transcriptional co-activator with PDZ-binding motif; YAP, Yes-associated protein; Dvl, dishevelled; Axin, axis inhibition protein; APC, adenomatous polyposis coli; GSK3, glycogen synthase kinase 3; CK1, casein kinase 1; $\beta$-cat, $\beta$-catenin; TCF, T-cell factor family; LEF, lymphocyte enhancer-binding factor.

is found to be elevated in the glaucomatous trabecular meshwork, and exogenous sFRP1 brings about high IOP $(96,97)$. In sFRP1-perfused human eyes, the level of $\beta$-catenin was shown to be significantly decreased. According to a recent study, sFRP1 is associated with cell stiffness (97). HTM cells have different responses to the stimulus of different concentrations of sFRP1 (97). It has been illustrated that sFRP1 is elevated in normal HTM cells grown on substrates that simulate the stiffness of the glaucomatous HTM. The increase in stiffness of the HTM enhances the aqueous humor outflow resistance and is conducive to elevated IOP (97). Additionally, one study revealed that a small molecule GSK $3 \beta$ inhibitor can increase the activity of the Wnt/ $\beta$-catenin pathway and remit ocular hypertension, which is caused by sFRP1 in mouse eyes (96) (Fig. 2). It has been reported that there may be two effects of Wnt in glaucoma (5). On one hand, the nuclear translocation of $\beta$-catenin influences gene expression (5). The glaucoma gene myocilin (MYOC) has been reported to be a regulator of Wnt/ $\beta$-catenin signaling (98). However, whether MYOC mutation affects Wnt in the HTM remains unclear. On the other hand, the aqueous humor outflow resistance is affected by the change in adhesion junctions and cell contact, and then IOP is regulated (5).
The Wnt/ $\beta$-catenin pathway is believed to be a novel interventional route for the treatment of glaucoma (99). The Wnt/ $\beta$-catenin pathway is influenced by YAP/TAZ, and YAP/TAZ exert an adverse effect on Wnt (5). Therefore, we speculate that there is a close association among the Wnt/ $\beta$-catenin pathway, the Hippo pathway and glaucoma. YAP/TAZ may be novel target genes for the treatment of glaucoma.

\section{Regulation of LPA in glaucoma and the mutual regulation with YAP/TAZ}

LPA, a glycerophospholipid-signaling molecule, exists in all tissues and serum (100). LPA is a small molecule regulating YAP/TAZ, and it can indirectly inhibit the activity of Lats1/2 and decrease the phosphorylation of YAP/TAZ at Ser127 (73). Various types of LPA isoforms have the same function (73). Only with cytoplasmic accumulation and 14-3-3 protein binding can YAP Ser127 be phosphorylated. Therefore, LPA also promotes the interaction between YAP and TEAD1 (Fig. 3). Aberrant expression of LPA receptors brings about the dephosphorylation and the nuclear accumulation of YAP/TAZ. YAP/TAZ serve a role in LPA-induced gene expression (73). Subsequent to 


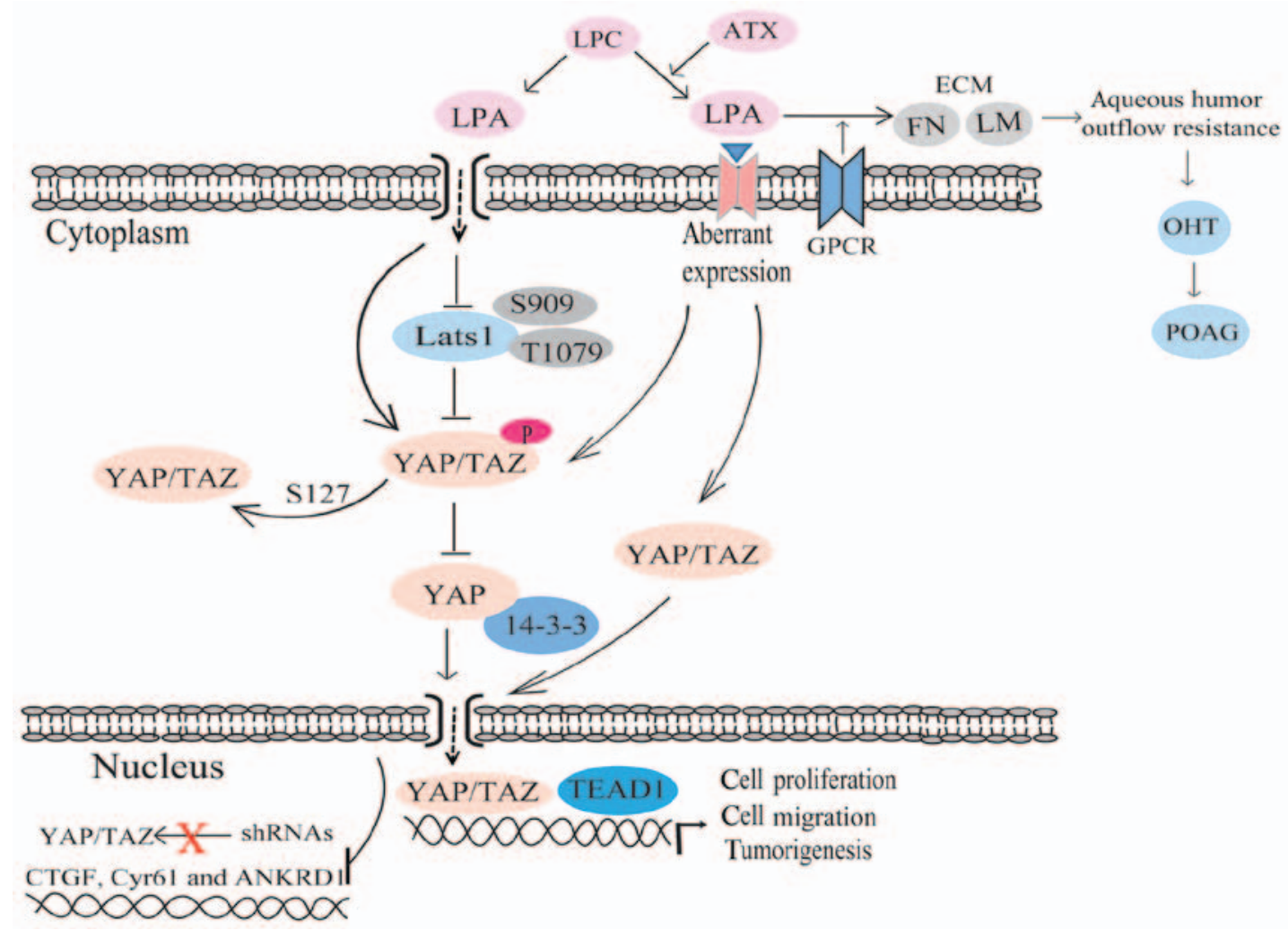

Figure 3. Regulation of LPA in glaucoma and the mutual regulation with YAP/TAZ. LPA inhibits the activity of Lats1/2 and decreases YAP/TAZ phosphorylation, leading to the inhibition of the interaction of YAP-14-3-3 and YAP nuclear localization. LPA promotes the interaction of YAP and TEAD1. LPA promotes the accumulation of FN and LM in the human trabecular meshwork via a G-protein-coupled receptor, result in an increase in the aqueous humor outflow and OHT, finally, leading to POAG. LPA, lysophosphatidic acid; YAP, Yes-associated protein; TAZ, transcriptional co-activator with PDZ-binding motif; TEAD, transcriptional enhancer factor TEF-1; FN, fibronectin; LM, laminin; OHT, ocular hypertension; POAG, primary open-angle glaucoma; LPA, lysophosphatidic acid; ATX, autotaxin; ECM, extracellular matrix; TEAD, transcriptional enhancer activator domain; FN, fibronectin; LM, laminin; POAG, primary open-angle glaucoma.

using short hairpin RNAs to knock out YAP/TAZ, the mRNA induction of CTGF, Cyr61 and ANKRD1 will be consumingly inhibited by LPA (73). In addition, LPA mediates cell proliferation (101), cell migration and the metastasis of certain cancer cells (102). Excessive expression of LPA receptors in mice leads to the hyperplasia of mammary glands and breast cancer (103).

LPA level increases in glaucoma and LPA inhibitors can reduce the IOP $(6,104)$. Elevated IOP is one of the major risk factors for the development of POAG, and it is caused by obstruction of the aqueous humor outflow (105). The chief outflow resistance of the aqueous humor has been located in the trabecular meshwork. Changes in the trabecular cells and ECM can directly or indirectly affect the aqueous humor outflow resistance (106). A previous study showed that autotaxin (ATX) and LPA exist in the aqueous humor in humans and a range of animals (107). Concentrations of ATX and LPA in the aqueous humor of patients with POAG are significantly higher than those of healthy people (107). FN and LM are the chief components of the ECM in the trabecular meshwork. It has been found that FN and LM are excessively deposited in POAG, leading to an increase in the aqueous humor outflow resistance (108). ATX is a key cytokine in the aqueous humor and its major function is to catalyze the generation of LPA (107). LPA can promote a variety of cells to synthesize the ECM through autocrine and paracrine functions, and its signaling transduction pathway primarily acts through G-protein-coupled receptors (73) (Fig. 3). Meanwhile,
LPA serves a major role in promoting proliferation, differentiation and interaction between cells (109). Thus, the ATX-LPA pathway may elevate IOP by promoting the synthesis of ECM in the HTM, and then increase the resistance of the aqueous humor outflow, participating in the process of POAG.

\section{Regulation of the TGF- $\beta$ /Smad signaling pathway in glaucoma and the interaction with YAP/TAZ}

TGF- $\beta$, which was first identified by Delarco and Todar in 1978 , is a type of multifunctional cytokine (110-112). TGF- $\beta$ has been found in almost all human cells, where it has a significant role in apoptosis, differentiation, the cell cycle, immunoregulation and the synthesis of the ECM via binding with its receptors (113). TGF- $\beta$ has five subtypes, and three of these, TGF- $\beta 1$, TGF- $\beta 2$ and TGF- $\beta 3$, are present in mammals, with homology of $70-80 \%$ (114). The signaling transduction of TGF- $\beta$ acts by combining its ligand with receptors that are the membrane-associated proteins on the cell membrane. Receptor types I, II and III participate in TGF- $\beta$-mediated signaling transduction. However, receptor type III only has a supporting role during the incorporation of ligand and receptors I/II in the transduction, as it has no serine/threonine activity. TGF- $\beta$ combines with the type II receptor, then the latter phosphorylates the type I receptor, which leads to the activation of this receptor (115). Later, activated type I receptor activates target 


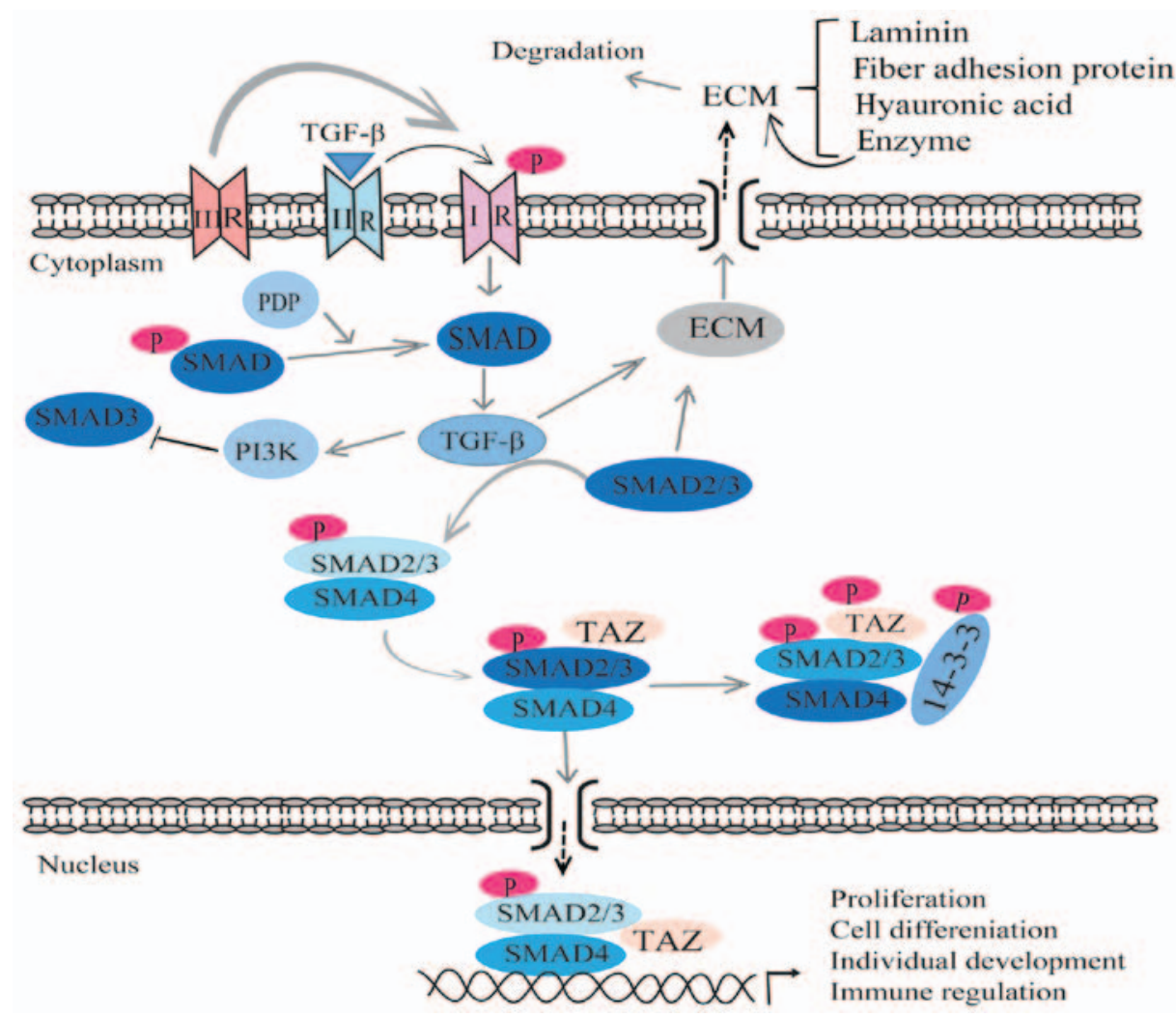

Figure 4. Regulation of the TGF- $\beta /$ Smad signaling pathway in glaucoma. TGF- $\beta$ combines with the type II receptor, then phosphorylates the type I receptor, leading to the activation of this type I receptor. TGF- $\beta 2$ promotes the synthesis of collagen protein and fiber connection protein, and inhibits the synthesis of hyaluronic acid. TGF- $\beta 2$ promotes enzymes to inhibit the accumulation of the ECM. The TMC can secrete enzymes, promoting the accumulation of the ECM and increasing the aqueous outflow resistance. SMADA2/3 promotes the accumulation of the ECM in the HTM, leading to an increase in the aqueous outflow resistance and ocular hypertension, finally resulting in primary open-angle glaucoma. TGF- $\beta$, transforming growth factor- $\beta$; ECM, extracellular matrix; TAZ, transcriptional co-activator with PDZ-binding motif; TMC, trabecular meshwork cell.

protein, such as SMAD protein, resulting in the activation of the signaling transduction of TGF- $\beta$ (115). The Smad family of proteins are key proteins in the process of TGF- $\beta$ signal transduction, and has numerous subtypes (116) (Fig. 4). The PI3K signaling pathway can be regulated by TGF- $\beta$. Inhibiting PI3K can reduce the activity of Smad3 (receptor activation SMAD protein) (117). Pyruvate dehydrogenase phosphatase can specifically dephosphorylate SMAD in Drosophila, indicating that SMAD is the core protein that mediates the signal transduction of TGF- $\beta$ (118). TGF- $\beta$ has numerous biological effects and can be expressed in various types of cells, with an important role in regulating cell proliferation, cell differentiation, synthesis, deposition and degradation of the ECM (119). In addition, TGF- $\beta$ mediates the individual development of growing, inflammatory process and the immune regulation (119).

Increasing aqueous outflow resistance is associated with the abnormal contraction and movement of the trabecular meshwork, as well the abnormal synthesis and secretion of the ECM. These abnormal activities cause the deposition of the ECM, and finally lead to a high IOP, and the damage of the structure and function of the eyes (4). A previous study proved that the human corneal endothelial layer, ciliary body, iris and trabecular meshwork can express and transcribe the RNA of TGF- $\beta 1$ and TGF- $\beta 2$ (120). Evidence has shown that the concentration of TGF- $\beta$ in the aqueous humor of patients with POAG is markedly higher than that in patients without POAG (121). In HTM cells, the constitutive expression and release of biologically active TGF- $\beta 2$ can be mediated by Q-GTPase signaling (122). Q-associated kinase inhibitors directly affect the TM and SC by controlling the synthesis of actin stress fibers, focal adhesion and cellular contraction $(123,124)$. Trabecular meshwork cells synthesize and secrete the components of the ECM, including laminin, fiber adhesion proteins, hyaluronic acid and enzymes that can degrade the ECM (7). Research has revealed that $\operatorname{Smad} 2 / 3$, which can stimulate the cell to synthesize ECM, is the key protein in the process of ECM reconstruction (115). The increasing secretion of the ECM and the reduction of Smad2/3 will lead to the accumulation of ECM and stop the aqueous outflow from increasing. Studies have indicated that TGF- $\beta$ can promote the synthesis of the ECM via regulation of trabecular meshwork cells, and then affect the aqueous human outflow resistance $(7,120,125)$. Experiments in pig eyes have found that TGF- $\beta 2$ can promote the synthesis of collagen protein and fiber connection protein. The synthesis of collagen protein and fiber connection protein inhibits the synthesis of hyaluronic acid and regulates the molecular structure of fiber connection protein. The proteolytic enzyme reduces the degradation of fiber link protein and then leads to the deposition of fiber connection protein, ultimately causing glaucoma (126) (Fig. 4). TGF- $\beta$ can also promote the synthesis of metalloproteinase tissue inhibitors to inhibit matrix metalloproteinases and the degradation of the ECM, which causes the deposition of ECM in the trabecular meshwork $(7,125)$. Overall, TGF- $\beta$ promotes the deposition of the ECM by promoting the synthesis of the ECM, regulating trabecular cells and altering 


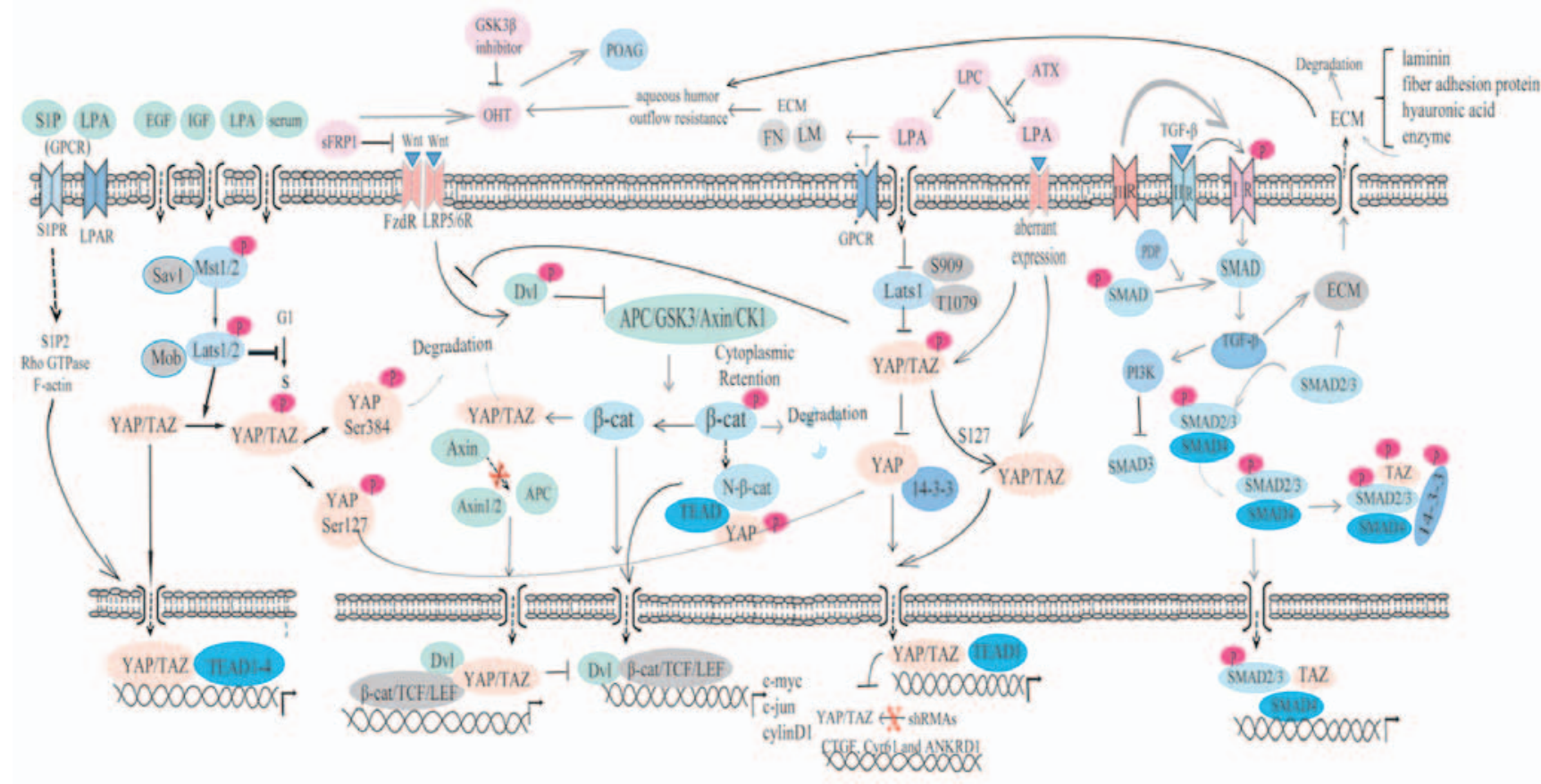

Figure 5. Regulation amongst the Wnt/ $\beta$-catenin, LPA and TGF- $\beta /$ Smad signaling pathways and YAP/TAZ of the Hippo pathway. The Wnt/ $\beta$-catenin, LPA and TGF- $\beta /$ Smad signaling pathways are all involed in the regulation of the pathogenesis of glaucoma. LPA, lysophosphatidic acid; TGF- $\beta$, transforming growth factor- $\beta$; YAP, Yes-associated protein; TAZ, transcriptional co-activator with PDZ-binding motif; Ex, expanded; Mer, Merlin; Sav, Salvador; Hpo, Hippo; Wts, Warts; Yki, Yorkie; Sd, Scalloped; S1P, sphingosine-1-phosphate; LPA, lysophosphatidic acid; GPCR, G-protein-coupled receptor; EGF, epidermal growth factor; IGF, insulin-like growth factor; S1PR, sphingosine-1-phosphate receptor; LPAR, Lysophosphatidic acid receptor; Mst1/2, Hpo orthologs; Lats1/2, Wts orthologs; Sav1, Sav orthologs; Mob, Mats orthologs; G1, the gap before DNA replication; S, DNA synthetic phase; TEAD, transcriptional enhancer activator domain; sFRP1, Secreted frizzled-related protein 1; OHT, ocular hypertensive; FzdR, Frizzled Receptors; LRP5/6R, low-density lipoprotein receptor-related protein 5 or 6; Dvl, Dishevelled; Axin, axis inhibition protein; APC, adenomatous polyposis coli; GSK3, glycogen synthase kinase 3; CK1, casein kinase 1; $\beta$-cat, $\beta$-catenin; TCF, T-cell factor family; LEF, lymphocyte enhancer-binding factor. Axin, axis inhibition protein; ATX, autotaxin; ECM, extracellular matrix; FN, fibronectin; LM, laminin; POAG, primary open-angle glaucoma.

the structure of the ECM. Enhancing the levels of inhibitors of protease can reduce the degradation of the ECM.

It has been found that TGF- $\beta$ can inhibit the proliferation of human trabecular cells stimulated by EGF (127). The reduction in the number of trabecular meshwork cells indicates that TGF- $\beta$ can inhibit trabecular cell proliferation and then participate in the pathogenesis of glaucoma. TGF- $\beta 1$ can enhance the expression of $\alpha$-actin mRNA in human and monkey trabecular meshwork cells. TGF- $\beta 1$ can promote the transfomation of the trabecular meshwork into fibroblasts, resulting in an increase in the contraction and motor function of the trabecular meshwork (128). Trabecular cell microfilament actin levels increased by TGF- $\beta 1$ can promote the ability of cell shrinkage and movement, which is conducive to the outflow of the aqueous humor. If the abilities of shrinkage and movement are excessively enhanced, the trabecular meshwork shrinks and loses elasticity. Atrophy and inelasticity of the trabecular meshwork act against the outflow of the aqueous humor and may cause the IOP to increase, leading to glaucoma.

Activated TGF- $\beta$ receptors phosphorylate SMAD2/3 on the C-terminal SSXS motif, and then the phosphorylated SMAD2/3 binds with SMAD4 to form a complex. TAZ can bind with the SMAD complex to promote the nuclear accumulation of SMAD (129). Lats can regulate the activity of the Hippo pathway and SMAD2/3 localization via YAP/TAZ. Studies of the regulation of TGF- $\beta /$ SMAD signaling in cells indicate that the Hippo kinase cascade may regulate SMAD nuclear localization by YAP/TAZ phosphorylation (9) (Fig. 4).

\section{Role of the YAP/TAZ gene in the development of glaucoma}

Glaucoma is one of the main causes of blindness worldwide (130). The core components of trabecular meshwork tissue are trabecular protein and the outer covering of trabecular meshwork cells. Trabecular meshwork cells are involved in engulfing, migrating, synthesizing and secreting the ECM, and transducing the signals between within the ECM (7). In addition, trabecular meshwork cells have the biological characteristic of adhering to the substrate of the ECM and serve an important role in maintaining the normal aqueous humor outflow pathways and controlling the IOP (131). In POAG, the resistance of the aqueous outflow increases, the stiffness of the trabecular meshwork enhances and the gap of trabecular meshwork structure narrows (131). Atomic force microscopy has confirmed that the stiffness of the trabecular meshwork of glaucoma patients is 20 times than that of the normal HTM (132). YAP and TAZ have been identified as the mechanical signal factors involved, and they are influenced by the stiffness of the ECM (133). As extracellular microenvironment power transduction factors and transcription activation factors, YAP/TAZ can directly be influenced by the elasticity and stiffness of the trabecular meshwork in glaucoma (134).

It has been demonstrated that YAP/TAZ exist in all levels of the trabecular meshwork (134), including juxtacanalicular tissue, which is considered to be the fundamental part of aqueous humor outflow resistance. YAP was confirmed to be reduced in the trabecular meshwork incubated in a stiff substrate, while TAZ level was increased (134). According to this difference, 
YAP principally serves an important role in normal trabecular tissue, while TAZ markedly affects glaucoma trabecular tissue (134). This result is different from that found in the study by Dupont et al (133), which observed that YAP and TAZ were both increased in mammalian epithelial cells that were cultured on a stiff substrate (133). This result may caused by different cell types exhibiting different reactions to YAP/TAZ (135). YAP acts as a power transduction factor, and its positive reaction in trabecular cells shows that they may be involved in the development of glaucoma. There is a mutual regulation among the newly discovered target paths of glaucoma treatment and YAP/TAZ, although there is no experimental report to verify this.

\section{Conclusions}

The present review attempted to highlight the important role of YAP/TAZ and the Wnt/ $\beta$-catenin, LPA and TGF- $\beta /$ Smad pathways, which are all involved in the regulation of the pathogenesis of glaucoma (Fig. 5). These signaling pathways have become novel target pathways in the treatment of glaucoma and they also regulate the Hippo pathway. We hypothesize that the Hippo pathway may serve an important role in the pathogenesis of glaucoma, and YAP/TAZ may become novel target genes in the treatment of glaucoma. However, certain problems require solving, including determining the specific pathogenesis of glaucoma, the manner in which upstream factors regulate the Hippo signaling pathway and investigating the definitive regulating mechanism of YAP/TAZ in glaucoma. Further study is also required into whether there any other relevant regulators mediating the Wnt/ $\beta$-catenin, LPA and TGF- $\beta /$ Smad pathways, and whether MYOC mutations affect Wnt signaling in the trabecular meshwork.

\section{Acknowledgements}

This review was supported by the National Science Foundation of China (grant no. 81300768), the Sichuan Science Foundation (grant no. 2015JY0183), the Sichuan Health and Family Planning Commission (grant no. 16ZD025) and the National Key Speciality Construction Project of Clinical Pharmacy (grant no. 30305030698).

\section{References}

1. Quigley HA: Open-angle glaucoma. N Engl J Med 328: 1097-1106, 1993.

2. Johnson M: 'What controls aqueous humour outflow resistance?' Exp Eye Res 82: 545-557, 2006.

3. Johnstone MA and Grant WG: Pressure-dependent changes in structures of the aqueous outflow system of human and monkey eyes. Am J Ophthalmol 75: 365-383, 1973.

4. Knepper PA, Goossens W, Hvizd M and Palmberg PF: Glycosaminoglycans of the human trabecular meshwork in primary open-angle glaucoma. Invest Ophthalmol Vis Sci 37: 1360-1367, 1996.

5. Mao W, Millar JC, Wang WH, Silverman SM, Liu Y, Wordinger RJ, Rubin JS, Pang IH and Clark AF: Existence of the canonical Wnt signaling pathway in the human trabecular meshwork. Invest Ophthalmol Vis Sci 53: 7043-7051, 2012.

6. Miller E, Yang J, DeRan M, Wu C, Su AI, Bonamy GM, Liu J, Peters EC and Wu X: Identification of serum-derived sphingosine-1-phosphate as a small molecule regulator of YAP. Chem Biol 19: 955-962, 2012.

7. Fleenor DL, Shepard AR, Hellberg PE, Jacobson N, Pang IH and Clark AF: TGFbeta2-induced changes in human trabecular meshwork: implications for intraocular pressure. Invest Ophthalmol Vis Sci 47: 226-234, 2006.
8. Varelas X, Miller BW, Sopko R, Song S, Gregorieff A, Fellouse FA, Sakuma R, Pawson T, Hunziker W, McNeill H, et al: The Hippo pathway regulates Wnt/beta-catenin signaling. Dev Cell 18: 579-591, 2010.

9. Varelas X, Samavarchi-Tehrani P, Narimatsu M, Weiss A, Cockburn K, Larsen BG, Rossant J and Wrana JL: The Crumbs complex couples cell density sensing to Hippo-dependent control of the TGF- $\beta$-SMAD pathway. Dev Cell 19: 831-844, 2010.

10. Kango-Singh $M$ and Singh A: Regulation of organ size: insights from the Drosophila Hippo signaling pathway. Dev Dyn 238: 1627-1637, 2009.

11. Saucedo LJ and Edgar BA: Filling out the Hippo pathway. Nat Rev Mol Cell Biol 8: 613-621, 2007.

12. Buttitta LA and Edgar BA: How size is controlled: from Hippos to Yorkies. Nat Cell Biol 9: 1225-1227, 2007.

13. Pan D: Hippo signaling in organ size control. Genes Dev 21: 886-897, 2007.

14. Zhao B, Lei QY and Guan KL: The Hippo-YAP pathway: new connections between regulation of organ size and cancer. Curr Opin Cell Biol 20: 638-646, 2008.

15. Yu FX and Guan KL: The Hippo pathway: regulators and regulations. Genes Dev 27: 355-371, 2013.

16. Justice RW, Zilian O, Woods DF, Noll M and Bryant PJ: The Drosophila tumor suppressor gene warts encodes a homolog of human myotonic dystrophy kinase and is required for the control of cell shape and proliferation. Genes Dev 9: 534-546, 1995.

17. Tapon N, Harvey KF, Bell DW, Wahrer DC, Schiripo TA, Haber D and Hariharan IK: Salvador promotes both cell cycle exit and apoptosis in Drosophila and is mutated in human cancer cell lines. Cell 110: 467-478, 2002.

18. Udan RS, Kango-Singh M, Nolo R, Tao C and Halder G: Hippo promotes proliferation arrest and apoptosis in the Salvador/Warts pathway. Nat Cell Biol 5: 914-920, 2003.

19. Lai ZC, Wei X, Shimizu T, Ramos E, Rohrbaugh M, Nikolaidis N, Ho LL and Li Y: Control of cell proliferation and apoptosis by mob as tumor suppressor, mats. Cell 120: 675-685, 2005.

20. Huang J, Wu S, Barrera J, Matthews K and Pan D: The Hippo signaling pathway coordinately regulates cell proliferation and apoptosis by inactivating Yorkie, the Drosophila homolog of YAP. Cell 122: 421-434, 2005.

21. Goulev Y, Fauny JD, Gonzalez-Marti B, Flagiello D, Silber J and Zider A: SCALLOPED interacts with YORKIE, the nuclear effector of the hippo tumor-suppressor pathway in Drosophila. Curr Biol 18: 435-441, 2008.

22. Zhao B, Ye X, Yu J, Li L, Li W, Li S, Yu J, Lin JD, Wang CY, Chinnaiyan AM, et al: TEAD mediates YAP-dependent gene induction and growth control. Genes Dev 22: 1962-1971, 2008.

23. Hilman D and Gat U: The evolutionary history of YAP and the hippo/YAP pathway. Mol Biol Evol 28: 2403-2417, 2011.

24. Zhao B, Li L and Guan KL: Hippo signaling at a glance. J Cell Sci 123: 4001-4006, 2010.

25. Rauskolb C, Pan G, Reddy BV, Oh H and Irvine KD: Zyxin links fat signaling to the hippo pathway. PLoS Biol 9: e1000624, 2011.

26. Bryant PJ, Huettner B, Held LI Jr, Ryerse J and Szidonya J: Mutations at the fat locus interfere with cell proliferation control and epithelial morphogenesis in Drosophila. Dev Biol 129: 541-554, 1988.

27. Poernbacher I, Baumgartner R, Marada SK, Edwards K and Stocker H: Drosophila Pez acts in Hippo signaling to restrict intestinal stem cell proliferation. Curr Biol 22: 389-396, 2012.

28. Hamaratoglu F, Willecke M, Kango-Singh M, Nolo R, Hyun E, Tao C, Jafar-Nejad $\mathrm{H}$ and Halder G: The tumour-suppressor genes NF2/Merlin and Expanded act through Hippo signalling to regulate cell proliferation and apoptosis. Nat Cell Biol 8: 27-36, 2006.

29. Zhao B, Tumaneng K and Guan KL: The Hippo pathway in organ size control, tissue regeneration and stem cell self-renewal. Nat Cell Biol 13: 877-883, 2011.

30. Yu J, Zheng Y, Dong J, Klusza S, Deng WM and Pan D: Kibra functions as a tumor suppressor protein that regulates Hippo signaling in conjunction with Merlin and Expanded. Dev Cell 18: 288-299, 2010.

31. Harvey KF, Zhang X and Thomas DM: The Hippo pathway and human cancer. Nat Rev Cancer 13: 246-257, 2013.

32. Robinson BS, Huang J, Hong Y and Moberg KH: Crumbs regulates Salvador/Warts/Hippo signaling in Drosophila via the FERM-domain protein Expanded. Curr Biol 20: 582-590, 2010.

33. Meng Z, Moroishi T and Guan KL: Mechanisms of Hippo pathway regulation. Genes Dev 30: 1-7, 2016. 
34. Sun S and Irvine KD: Cellular organization and cytoskeletal regulation of the Hippo signaling network. Trends Cell Biol 26: 694-704, 2016.

35. Tyler DM and Baker NE: Expanded and fat regulate growth and differentiation in the Drosophila eye through multiple signaling pathways. Dev Biol 305: 187-201, 2007.

36. Willecke M, Hamaratoglu F, Kango-Singh M, Udan R, Chen CL, Tao C, Zhang X and Halder G: The fat cadherin acts through the Hippo tumor-suppressor pathway to regulate tissue size. Curr Biol 16: 2090-2100, 2006.

37. McCartney BM, Kulikauskas RM, LaJeunesse DR and Fehon RG: The neurofibromatosis-2 homologue, Merlin, and the tumor suppressor expanded function together in Drosophila to regulate cell proliferation and differentiation. Development 127 1315-1324, 2000.

38. Baumgartner R, Poernbacher I, Buser N, Hafen E and Stocker H: The WW domain protein Kibra acts upstream of Hippo in Drosophila. Dev Cell 18: 309-316, 2010.

39. Tikoo A, Varga M, Ramesh V, Gusella J and Maruta H: An anti-Ras function of neurofibromatosis type 2 gene product (NF2/Merlin). J Biol Chem 269: 23387-23390, 1994.

40. Yi C and Kissil JL: Merlin in organ size control and tumorigenesis: Hippo versus EGFR? Genes Dev 24: 1673-1679, 2010.

41. Chen CL, Gajewski KM, Hamaratoglu F, Bossuyt W Sansores-Garcia L, Tao C and Halder G: The apical-basal cell polarity determinant Crumbs regulates Hippo signaling in Drosophila. Proc Natl Acad Sci USA 107: 15810-15815, 2010.

42. Edgar BA: From cell structure to transcription: Hippo forges a new path. Cell 124: 267-273, 2006.

43. Avruch J, Zhou D, Fitamant J and Bardeesy N: Mst1/2 signalling to Yap: gatekeeper for liver size and tumour development. Br J Cancer 104: 24-32, 2011.

44. Wu S, Huang J, Dong J and Pan D: Hippo encodes a Ste-20 family protein kinase that restricts cell proliferation and promotes apoptosis in conjunction with salvador and warts. Cell 114: 445-456, 2003.

45. Chan EH, Nousiainen M, Chalamalasetty RB, Schäfer A, Nigg EA and Silljé HH: The Ste20-like kinase Mst2 activates the human large tumor suppressor kinase Lats1. Oncogene 24: 2076-2086, 2005.

46. Callus BA, Verhagen AM and Vaux DL: Association of mammalian sterile twenty kinases, Mst1 and Mst2, with hSalvador via C-terminal coiled-coil domains, leads to its stabilization and phosphorylation. FEBS J 273: 4264-4276, 2006.

47. Li Y, Pei J, Xia H, Ke H, Wang H and Tao W: Lats2, a putative tumor suppressor, inhibits G1/S transition. Oncogene 22 4398-4405, 2003.

48. Xia H, Qi H, Li Y, Pei J, Barton J, Blackstad M, Xu T and Tao W: LATS1 tumor suppressor regulates G2/M transition and apoptosis. Oncogene 21: 1233-1241, 2002.

49. Yang X, Li DM, Chen W and Xu T: Human homologue of Drosophila lats, LATS1, negatively regulate growth by inducing $\mathrm{G}(2) / \mathrm{M}$ arrest or apoptosis. Oncogene 20: 6516-6523, 2001.

50. Pan D: The Hippo signaling pathway in development and cancer. Dev Cell 19: 491-505, 2010.

51. Zhao B, Li L, Lei Q and Guan KL: The Hippo-YAP pathway in organ size control and tumorigenesis: an updated version. Genes Dev 24: 862-874, 2010

52. Zhang X, George J, Deb S, Degoutin JL, Takano EA, Fox SB, Bowtell DD and Harvey KF; AOCS Study group: The Hippo pathway transcriptional co-activator, YAP, is an ovarian cancer oncogene. Oncogene 30: 2810-2822, 2011.

53. Sudol M: Yes-associated protein (YAP65) is a proline-rich phosphoprotein that binds to the $\mathrm{SH} 3$ domain of the Yes proto-oncogene product. Oncogene 9: 2145-2152, 1994.

54. Dong J, Feldmann G, Huang J, Wu S, Zhang N, Comerford SA, Gayyed MF, Anders RA, Maitra A and Pan D: Elucidation of a universal size-control mechanism in Drosophila and mammals. Cell 130: 1120-1133, 2007.

55. Zender L, Spector MS, Xue W, Flemming P, Cordon-Cardo C, Silke J, Fan ST, Luk JM, Wigler M, Hannon GJ, et al: Identification and validation of oncogenes in liver cancer using an integrative oncogenomic approach. Cell 125: 1253-1267, 2006.

56. Overholtzer M, Zhang J, Smolen GA, Muir B, Li W, Sgroi DC, Deng CX, Brugge JS and Haber DA: Transforming properties of YAP, a candidate oncogene on the chromosome 11q22 amplicon. Proc Natl Acad Sci USA 103: 12405-12410, 2006

57. Chen L, Chan SW, Zhang X, Walsh M, Lim CJ, Hong W and Song H: Structural basis of YAP recognition by TEAD4 in the Hippo pathway. Genes Dev 24: 290-300, 2010.

58. $\mathrm{Oh} \mathrm{H}$ and Irvine KD: In vivo regulation of Yorkie phosphorylation and localization. Development 135: 1081-1088, 2008.
59. Oh $\mathrm{H}$ and Irvine KD: Yorkie: the final destination of Hippo signaling. Trends Cell Biol 20: 410-417, 2010.

60. Zhao B, Wei X, Li W, Udan RS, Yang Q, Kim J, Xie J, Ikenoue T, $\mathrm{Yu} \mathrm{J}, \mathrm{Li} \mathrm{L}$, et al: Inactivation of YAP oncoprotein by the Hippo pathway is involved in cell contact inhibition and tissue growth control. Genes Dev 21: 2747-2761, 2007.

61. Kanai F, Marignani PA, Sarbassova D, Yagi R, Hall RA, Donowitz M, Hisaminato A, Fujiwara T, Ito Y, Cantley LC, et al: TAZ: a novel transcriptional co-activator regulated by interactions with 14-3-3 and PDZ domain proteins. EMBO J 19: 6778-6791, 2000.

62. Yaffe MB, Rittinger K, Volinia S, Caron PR, Aitken A, Leffers H, Gamblin SJ, Smerdon SJ and Cantley LC: The structural basis for 14-3-3:phosphopeptide binding specificity. Cell 91: 961-971, 1997.

63. Lei QY, Zhang H, Zhao B, Zha ZY, Bai F, Pei XH, Zhao S, Xiong Y and Guan KL: TAZ promotes cell proliferation and epithelial-mesenchymal transition and is inhibited by the Hippo pathway. Mol Cell Biol 28: 2426-2436, 2008.

64. Basu S, Totty NF, Irwin MS, Sudol M and Downward J: Akt phosphorylates the Yes-associated protein, YAP, to induce interaction with 14-3-3 and attenuation of p73-mediated apoptosis. Mol Cell 11: 11-23, 2003.

65. Zhao B, Li L, Tumaneng K, Wang CY and Guan KL: A coordinated phosphorylation by Lats and $\mathrm{CK} 1$ regulates YAP stability through SCF(beta-TRCP). Genes Dev 24: 72-85, 2010.

66. Liu CY, Zha ZY, Zhou X, Zhang H, Huang W, Zhao D, Li T, Chan SW, Lim CJ, Hong W, et al: The Hippo tumor pathway promotes TAZ degradation by phosphorylating a phosphodegron and recruiting the SCF beta\}-TrCP E3 ligase. J Biol Chem 285: 37159-37169, 2010.

67. Camargo FD, Gokhale S, Johnnidis JB, Fu D, Bell GW, Jaenisch R and Brummelkamp TR: YAP1 increases organ size and expands undifferentiated progenitor cells. Curr Biol 17: 2054-2060, 2007.

68. Da CL, Xin Y, Zhao J and Luo XD: Significance and relationship between Yes-associated protein and survivin expression in gastric carcinoma and precancerous lesions. World J Gastroenterol 15: 4055-4061, 2009.

69. Wang X, Su L and Ou Q: Yes-associated protein promotes tumour development in luminal epithelial derived breast cancer. Eur J Cancer 48: 1227-1234, 2012.

70. Lam-Himlin DM, Daniels JA, Gayyed MF, Dong J, Maitra A, Pan D, Montgomery EA and Anders RA: The Hippo pathway in human upper gastrointestinal dysplasia and carcinoma: a novel oncogenic pathway. Int J Gastrointest Cancer 37: 103-109, 2006.

71. Wada K, Itoga K, Okano T, Yonemura S and Sasaki H: Hippo pathway regulation by cell morphology and stress fibers. Development 138: 3907-3914, 2011.

72. Straßburger K, Tiebe M, Pinna F, Breuhahn K and Teleman AA: Insulin/IGF signaling drives cell proliferation in part via Yorkie/YAP. Dev Biol 367: 187-196, 2012.

73. Yu FX, Zhao B, Panupinthu N, Jewell JL, Lian I, Wang LH, Zhao J, Yuan H, Tumaneng K, Li H, et al: Regulation of the Hippo-YAP pathway by G-protein-coupled receptor signaling. Cell 150: 780-791, 2012.

74. Fan R, Kim NG and Gumbiner BM: Regulation of Hippo pathway by mitogenic growth factors via phosphoinositide 3-kinase and phosphoinositide-dependent kinase-1. Proc Natl Acad Sci USA 110: 2569-2574, 2013.

75. MacDonald BT, Tamai K and He X: Wnt/beta-catenin signaling: components, mechanisms, and diseases. Dev Cell 17: 9-26, 2009.

76. Kikuchi A, Yamamoto $\mathrm{H}$ and Sato A: Selective activation mechanisms of Wnt signaling pathways. Trends Cell Biol 19: 119-129, 2009.

77. He X, Semenov M, Tamai K and Zeng X: LDL receptor-related proteins 5 and 6 in Wnt/beta-catenin signaling: arrows point the way. Development 131: 1663-1677, 2004.

78. Hoffmeyer K, Raggioli A, Rudloff S, Anton R, Hierholzer A, Del Valle I, Hein K, Vogt R and Kemler R: Wnt/ $\beta$-catenin signaling regulates telomerase in stem cells and cancer cells. Science 336: 1549-1554, 2012.

79. Ouyang $\mathrm{H}$, Zhuo $\mathrm{Y}$ and Zhang $\mathrm{K}$ : WNT signaling in stem cell differentiation and tumor formation. J Clin Invest 123: 1422-1424, 2013

80. Xing Y, Clements WK, Kimelman D and Xu W: Crystal structure of a beta-catenin/axin complex suggests a mechanism for the beta-catenin destruction complex. Genes Dev 17: 2753-2764, 2003.

81. Habas R and Dawid IB: Dishevelled and Wnt signaling: is the nucleus the final frontier? J Biol 4: 2, 2005. 
82. Tolwinski NS, Wehrli M, Rives A, Erdeniz N, DiNardo S and Wieschaus E: Wg/Wnt signal can be transmitted through arrow/LRP5,6 and Axin independently of Zw3/Gsk3beta activity. Dev Cell 4: 407-418, 2003.

83. Satoh S, Daigo Y, Furukawa Y, Kato T, Miwa N, Nishiwaki T, Kawasoe T, Ishiguro H, Fujita M, Tokino T, et al: AXIN1 mutations in hepatocellular carcinomas, and growth suppression in cancer cells by virus-mediated transfer of AXIN1. Nat Genet 24: 245-250, 2000.

84. Giles RH, van Es JH and Clevers H: Caught up in a Wnt storm: Wnt signaling in cancer. Biochim Biophys Acta 1653: 1-24, 2003

85. Cong F, Schweizer L and Varmus H: Wnt signals across the plasma membrane to activate the beta-catenin pathway by forming oligomers containing its receptors, Frizzled and LRP. Development 131: 5103-5115, 2004.

86. Cliffe A, Hamada F and Bienz M: A role of Dishevelled in relocating Axin to the plasma membrane during wingless signaling. Curr Biol 13: 960-966, 2003.

87. Saito-Diaz K, Chen TW, Wang X, Thorne CA, Wallace HA, Page-McCaw A and Lee E: The way Wnt works: components and mechanism. Growth Factors 31: 1-31, 2013.

88. Gan XQ, Wang JY, Xi Y, Wu ZL, Li YP and Li L: Nuclear Dvl, c-Jun, beta-catenin, and TCF form a complex leading to stabilization of beta-catenin-TCF interaction. J Cell Biol 180 1087-1100, 2008.

89. Itoh K, Brott BK, Bae GU, Ratcliffe MJ and Sokol SY: Nuclear localization is required for Dishevelled function in Wnt/beta-catenin signaling. J Biol 4: 3, 2005.

90. Azzolin L, Zanconato F, Bresolin S, Forcato M, Basso G, Bicciato S, Cordenonsi $\mathrm{M}$ and Piccolo S: Role of TAZ as mediator of Wnt signaling. Cell 151: 1443-1456, 2012.

91. Heallen T, Zhang M, Wang J, Bonilla-Claudio M, Klysik E, Johnson RL and Martin JF: Hippo pathway inhibits Wnt signaling to restrain cardiomyocyte proliferation and heart size. Science 332: 458-461, 2011.

92. Willert K, Shibamoto S and Nusse R: Wnt-induced dephosphorylation of axin releases beta-catenin from the axin complex. Genes Dev 13: 1768-1773, 1999.

93. Li VS, Ng SS, Boersema PJ, Low TY, Karthaus WR, Gerlach JP, Mohammed S, Heck AJ, Maurice MM, Mahmoudi T, et al: Wnt signaling through inhibition of $\beta$-catenin degradation in an intact Axin1 complex. Cell 149: 1245-1256, 2012

94. Konsavage WM Jr, Kyler SL, Rennoll SA, Jin G and Yochum GS : $\mathrm{Wnt} / \beta$-catenin signaling regulates Yes-associated protein (YAP) gene expression in colorectal carcinoma cells. J Biol Chem 287 $11730-11739,2012$

95. Azzolin L, Panciera T, Soligo S, Enzo E, Bicciato S, Dupont S Bresolin S, Frasson C, Basso G, Guzzardo V, et al: YAP/TAZ incorporation in the $\beta$-catenin destruction complex orchestrates the Wnt response. Cell 158: 157-170, 2014

96. Wang WH, McNatt LG, Pang IH, Millar JC, Hellberg PE, Hellberg MH, Steely HT, Rubin JS, Fingert JH, Sheffield VC, et al: Increased expression of the WNT antagonist sFRP-1 in glaucoma elevates intraocular pressure. J Clin Invest 118: 1056-1064, 2008

97. Morgan JT, Raghunathan VK, Chang YR, Murphy CJ and Russell P: Wnt inhibition induces persistent increases in intrinsic stiffness of human trabecular meshwork cells. Exp Eye Res 132: 174-178, 2015.

98. Kwon HS, Lee HS, Ji Y, Rubin JS and Tomarev SI: Myocilin is a modulator of Wnt signaling. Mol Cell Biol 29: 2139-2154, 2009.

99. Tovar-Vidales T, Roque R, Clark AF and Wordinger RJ: Tissue transglutaminase expression and activity in normal and glaucomatous human trabecular meshwork cells and tissues. Invest Ophthalmol Vis Sci 49: 622-628, 2008.

100. Choi JW, Herr DR, Noguchi K, Yung YC, Lee CW, Mutoh T, Lin ME, Teo ST, Park KE, Mosley AN, et al: LPA receptors: subtypes and biological actions. Annu Rev Pharmacol Toxicol 50: 157-186, 2010.

101.van Corven EJ, Groenink A, Jalink K, Eichholtz T and Moolenaar WH: Lysophosphatidate-induced cell proliferation: identification and dissection of signaling pathways mediated by G proteins. Cell 59: 45-54, 1989.

102. Shida D, Kitayama J, Yamaguchi H, Okaji Y, Tsuno NH, Watanabe T, Takuwa Y and Nagawa H: Lysophosphatidic acid (LPA) enhances the metastatic potential of human colon carcinoma DLD1 cells through LPA1. Cancer Res 63 1706-1711, 2003.

103. Liu S, Umezu-Goto M, Murph M, Lu Y, Liu W, Zhang F, Yu S Stephens LC, Cui X, Murrow G, et al: Expression of autotaxin and lysophosphatidic acid receptors increases mammary tumorigenesis, invasion, and metastases. Cancer Cell 15 539-550, 2009.
104. Rohen JW: Why is intraocular pressure elevated in chronic simple glaucoma? Anatomical considerations. Ophthalmology 90: $758-765,1983$.

105. No authors listed: The Advanced Glaucoma Intervention Study (AGIS): 7. The relationship between control of intraocular pressure and visual field deterioration. The AGIS Investigators. Am J Ophthalmol 130: 429-440, 2000.

106. Gasiorowski JZ and Russell P: Biological properties of trabecular meshwork cells. Exp Eye Res 88: 671-675, 2009.

107. Iyer P, Lalane R III, Morris C, Challa P, Vann R and Rao PV Autotaxin-lysophosphatidic acid axis is a novel molecular target for lowering intraocular pressure. PLoS One 7: e42627, 2012.

108. Li AF, Tane N and Roy S: Fibronectin overexpression inhibits trabecular meshwork cell monolayer permeability. Mol Vis 10 750-757, 2004

109. Willier S, Butt E and Grunewald TG: Lysophosphatidic acid (LPA) signalling in cell migration and cancer invasion: a focussed review and analysis of LPA receptor gene expression on the basis of more than 1700 cancer microarrays. Biol Cell 105: 317-333, 2013.

110. De Larco JE and Todaro GJ: Growth factors from murine sarcoma virus-transformed cells. Proc Natl Acad Sci USA 75: 4001-4005, 1978

111. Todaro GJ and De Larco JE: Growth factors produced by sarcoma virus-transformed cells. Cancer Res 38: 4147-4154, 1978.

112. Roberts AB, Lamb LC, Newton DL, Sporn MB, De Larco JE and Todaro GJ: Transforming growth factors: isolation of polypeptides from virally and chemically transformed cells by acid/ethanol extraction. Proc Natl Acad Sci USA 77: 3494-3498, 1980.

113. Pena RA, Jerdan JA and Glaser BM: Effects of TGF-beta and TGF-beta neutralizing antibodies on fibroblast-induced collagen gel contraction: implications for proliferative vitreoretinopathy. Invest Ophthalmol Vis Sci 35: 2804-2808, 1994

114. Border WA, Noble NA, Yamamoto T, Harper JR, Yamaguchi Yu, Pierschbacher MD and Ruoslahti E: Natural inhibitor of transforming growth factor-beta protects against scarring in experimental kidney disease. Nature 360: 361-364, 1992.

115.Zode GS, Sethi A, Brun-Zinkernagel AM, Chang IF, Clark AF and Wordinger RJ: Transforming growth factor- $\beta 2$ increases extracellular matrix proteins in optic nerve head cells via activation of the Smad signaling pathway. Mol Vis 17: $1745-1758,2011$

116. Itoh S, Itoh F, Goumans MJ and Ten Dijke P: Signaling of transforming growth factor-beta family members through Smad proteins. Eur J Biochem 267: 6954-6967, 2000.

117. Dupont J, McNeilly J, Vaiman A, Canepa S, Combarnous Y and Taragnat C: Activin signaling pathways in ovine pituitary and LbetaT2 gonadotrope cells. Biol Reprod 68: 1877-1887, 2003.

118. Chen HB, Shen J, Ip YT and Xu L: Identification of phosphatases for Smad in the BMP/DPP pathway. Genes Dev 20 648-653, 2006.

119. Eisenstein R and Grant-Bertacchini D: Growth inhibitory activities in avascular tissues are recognized by anti-transforming growth factor beta antibodies. Curr Eye Res 10: 157-162, 1991.

120. Tripathi RC, Li J, Chan WF and Tripathi BJ: Aqueous humor in glaucomatous eyes contains an increased level of TGF-beta 2. Exp Eye Res 59: 723-727, 1994.

121. Inatani M, Tanihara $\mathrm{H}$, Katsuta $\mathrm{H}$, Honjo $\mathrm{M}$, Kido $\mathrm{N}$ and Honda Y: Transforming growth factor-beta 2 levels in aqueous humor of glaucomatous eyes. Graefes Arch Clin Exp Ophthalmol 239: 109-113, 2001.

122. Pervan CL, Lautz JD, Blitzer AL, Langert KA and Stubbs EB Jr: Rho GTPase signaling promotes constitutive expression and release of TGF- $\beta 2$ by human trabecular meshwork cells. Exp Eye Res 146: 95-102, 2016.

123. RaoPV,Deng PF,KumarJ andEpstein DL: Modulation of aqueous humor outflow facility by the Rho kinase-specific inhibitor Y-27632. Invest Ophthalmol Vis Sci 42: 1029-1037, 2001

124. Inoue $\mathrm{T}$ and Tanihara H: Rho-associated kinase inhibitors: a novel glaucoma therapy. Prog Retin Eye Res 37: 1-12, 2013.

125. Takai Y, Tanito M and Ohira A: Multiplex cytokine analysis of aqueous humor in eyes with primary open-angle glaucoma, exfoliation glaucoma, and cataract. Invest Ophthalmol Vis Sci 53: 241-247, 2012

126. Li J, Tripathi BJ and Tripathi RC: Modulation of pre-mRNA splicing and protein production of fibronectin by TGF-beta2 in porcine trabecular cells. Invest Ophthalmol Vis Sci 41: $3437-3443,2000$ 
127. Wordinger RJ, Clark AF, Agarwal R, Lambert W, McNatt L, Wilson SE, Qu Z and Fung BK: Cultured human trabecular meshwork cells express functional growth factor receptors. Invest Ophthalmol Vis Sci 39: 1575-1589, 1998.

128. Tamm ER, Siegner A, Baur A and Lütjen-Drecoll E: Transforming growth factor-beta 1 induces alpha-smooth muscle-actin expression in cultured human and monkey trabecular meshwork. Exp Eye Res 62: 389-397, 1996.

129. Varelas X, Sakuma R, Samavarchi-Tehrani P, Peerani R, Rao BM, Dembowy J, Yaffe MB, Zandstra PW and Wrana JL: TAZ controls Smad nucleocytoplasmic shuttling and regulates human embryonic stem-cell self-renewal. Nat Cell Biol 10: 837-848, 2008

130. Quigley HA and Broman AT: The number of people with glaucoma worldwide in 2010 and 2020. Br J Ophthalmol 90: 262-267, 2006.

131. Tamm ER:The trabecular meshwork outflow pathways: structural and functional aspects. Exp Eye Res 88: 648-655, 2009.

132. Last JA, Pan T, Ding Y, Reilly CM, Keller K, Acott TS, Fautsch MP, Murphy CJ and Russell P: Elastic modulus determination of normal and glaucomatous human trabecular meshwork. Invest Ophthalmol Vis Sci 52: 2147-2152, 2011.
133. Dupont S, Morsut L, Aragona M, Enzo E, Giulitti S, Cordenonsi M, Zanconato F, Le Digabel J, Forcato M, Bicciato S, et al: Role of YAP/TAZ in mechanotransduction. Nature 474: 179-183, 2011.

134. Raghunathan VK, Morgan JT, Dreier B, Reilly CM, Thomasy SM, Wood JA, Ly I, Tuyen BC, Hughbanks M, Murphy CJ, et al: Role of substratum stiffness in modulating genes associated with extracellular matrix and mechanotransducers YAP and TAZ. Invest Ophthalmol Vis Sci 54: 378-386, 2013.

135. Comes N, Buie LK and Borras T: Evidence for a role of angiopoietin-like 7 (ANGPTL7) in extracellular matrix formation of the human trabecular meshwork: implications for glaucoma. Genes Cells 16: 243-259, 2011.

This work is licensed under a Creative Commons Attribution-NonCommercial-NoDerivatives 4.0 International (CC BY-NC-ND 4.0) License. 